\title{
Effects of Joints Inclination Angle on Failure Properties of Rock Masses Under Directly Tensile
}

\author{
Lie-xian TANG ${ }^{1, a}$ \\ ${ }^{1}$ School of Mining Engineering, University of Science and Technology Liaoning, An-shan, China \\ at7766@sina.com
}

\begin{abstract}
Keywords: Joint Inclined Angle; Failure of Rock Masses; Directly Tensile; Numerical Tests
Abstract. Usually joints will produce decisive effects to failure properties of rock masses. This paper finished numerical tests of failure process on jointed rock masses with different inclined angles in directly tensile, found that the location and direction of main crack on rock masses without joint were uncertain and random, the peak strength was highest. The main cracks of jointed rock masses were effected obviously with joints, excepted the joint inclined angle was $90^{\circ}$, all main cracks connected with high and low points of joints in almost horizontal levels. All peak strength of jointed rock masses were lower than rock masses without joint. The peak strength were raised with the inclined angles bigger and bigger, even the peak strength was close to the rock masses without joint which the joints inclined angles was $90^{\circ}$. Clearly, the joint inclined angle affects obviously the strength and failure properties of rock masses, so we should adopt different design basing on the stress direction of rock masses and the joints inclined angle to ensure the safety and efficient of engineering .
\end{abstract}

\section{Introduction}

In mining, hydroelectric power, civil engineering and traffic engineering, we often need to design and construction in or on the rock masses, such as all kinds of tunnels or rooms in mining engineering, tunnels of hydropower or traffic engineering and slopes of open-pit mine or transport and hydroelectric power engineering, etc. Natural rock masses are consist of unbroken rock and different discontinuity faces, the discontinuity faces mainly include faults and joints, they produce decisive influence to the mechanical behavior of rock masses. To ensure the security and economy of rock mass engineering, so correctly understand the deformation and failure properties of rock masses with discontinuity faces is very important.

Mechanics effect of discontinuity faces in rock mass is connected with the mechanical properties and geometric features of fracture faces. Scholars at home and abroad carried out a large amount of physical simulation experiments research in terms of joint rock mechanical characteristics, such as Brown, E T [1] studied the joint spacing, the number of groups, the penetration rate of the influence of rock mass strength, deformation and failure mode through the pile of masonry triaxial compression test; Shi-wei Bai [2], studied a single and two horizontal joints in different joint connected rate, the change rule and failure mechanism under the condition of different normal stress, shear deformation and strength characteristics; Bobet A [3] studied the fracture penetration mechanism of rock modeling material specimen under uniaxial compression test under the condition of secondary crack initiation, expansion, and the convergence of specimen; Hong-kai Chen, Hong-mei Tang [4] studied the calculation method of structural surface with master dangerous rock strength parameters; R.P. Tiwari and k. Seshagiri [5] studied the influence of strain hardening and strain softening and plastic behavior by pile of masonry true triaxial compression test of rock mass joint geometry and stress level; In the study of structural plane mechanical properties, Barton-Bandis model reflects the influence of the structural plane on the structure of surface roughness, rock strength, opening, filling situation and seepage on the shear properties in quantitative model[6], and obtained the widespread application and development. And the influence of geometric parameters such as the group number, occurrence, continuity, density, configuration mode of fracture surface on the macroscopic mechanical behavior of rock mass, because of its diversity of spatial distribution and the combination of stress state, 
strength, deformation and failure characteristics of rock mass are anisotropy and complexity, so far it is one of the hot spot and the difficulty on rock mechanics research.

Joint spacing of jointed rock is in metric magnitude, so the representative volume element (RVE) is very large, but it is not easy to $1 \mathrm{~m}$ size in large rock mechanics tests, using indoor test directly to measure its mechanical characteristics is unrealistic. The influencing factors in situ test of rock mass are more, test results are large discreteness and very expensive [7]. Indoor physical model test can systematically and controlled research impact effect of system parameters in jointed rock mass, so it is widely used to explore the strength, deformation and failure mechanism of jointed rock mass, but the indoor physical experiment model making difficulties and high costs, long test periods, poor repeatability and difficulty to collect data, therefore, this article adopts the numerical tests method, to carry out the failure process of rock masses under the conditions of different joints, in order to obtain the generalized rules of failure properties on jointed rock masses with different joints, and provide a reference basis for rock mass engineering design.

\section{Conditions of Numerical Tests}

\section{Model Parameters}

Joints in rock mass usually produce a decisive influence on failure properties of rock mass, and different length, angle, spacing, and the number of different groups of joints can produce different effects, so the different occurrence joint research with the same mechanical parameters on the influence of rock mass damage characteristics, it has important significance to understand the failure mechanism of jointed rock mass and guide the design and construction of rock engineering. Although joints in rock mass exist in the form of many groups, but the spacing is often larger, even as the level meters, therefore, this paper studies the directly tensile tests under the condition of failure process of sample as the standard uniaxial compression test models, small size, so only consider one precast joint situation, through the same joint trace length and different angle to study the influence of joint on strength and deformation characteristics of rock mass with directly tensile. The diameter of the model is $5 \mathrm{~cm}$ and the height is $10 \mathrm{~cm}$, because this article only studies general failure properties of joint rock, not for a particular rock mass, so the model parameters is assumed parameters referenced test results and as shown in table 1.

Table1 Physical and Mechanics Parameters of Numerical Models

\begin{tabular}{|c|c|c|c|c|c|}
\hline name & $\begin{array}{l}\text { Compressive } \\
\text { Strength }(\mathrm{MPa})\end{array}$ & $C / T$ & $\begin{array}{l}\text { elasticity } \\
\text { modulus ( } M P a)\end{array}$ & $\begin{array}{l}\text { Poisson's } \\
\text { ratio }\end{array}$ & $\begin{array}{l}\text { internal friction } \\
\text { angle }\left({ }^{\circ}\right)\end{array}$ \\
\hline Parameters & 35 & 10 & 38600 & 0.25 & 30 \\
\hline
\end{tabular}

Models and Loading Conditions

Numerical tests using rock failure process analysis system RFPA-2D[8], unit number is $200 * 100$, for the directly tensile loading way, the load loading and each step loading $0.02 \mathrm{MPa}$. Considering the heterogeneity of rock material, set up three same parameter models each joint angle of model, calculation results take its average. Joint trace length is set to $25 \mathrm{~mm}$ and the width is set to $1 \mathrm{~mm}$, and the center of the joint mediate, $30 \mathrm{~mm}$ to the top of model, assume joint without fillings, finished 10 numerical models including without joint, joint inclined angle is $0^{\circ}, 10^{\circ}, 20^{\circ}, 30^{\circ}, 40^{\circ}, 50^{\circ}, 60^{\circ}$, $70^{\circ}, 80^{\circ}, 90^{\circ}$, numerical models are shown in figure 1. 


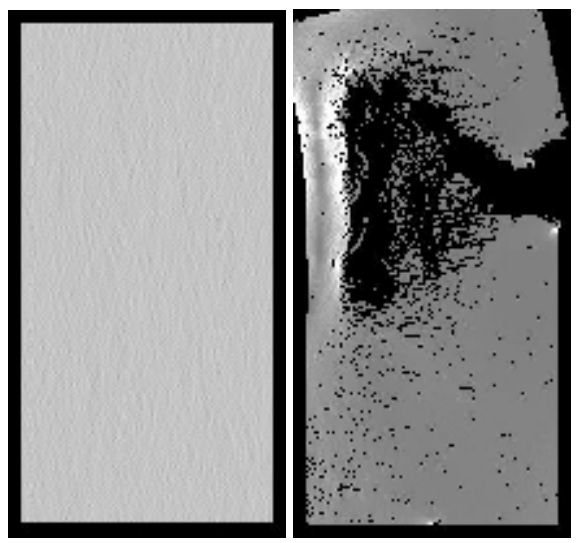

Rock mass without joint and the failure result in directly tensile
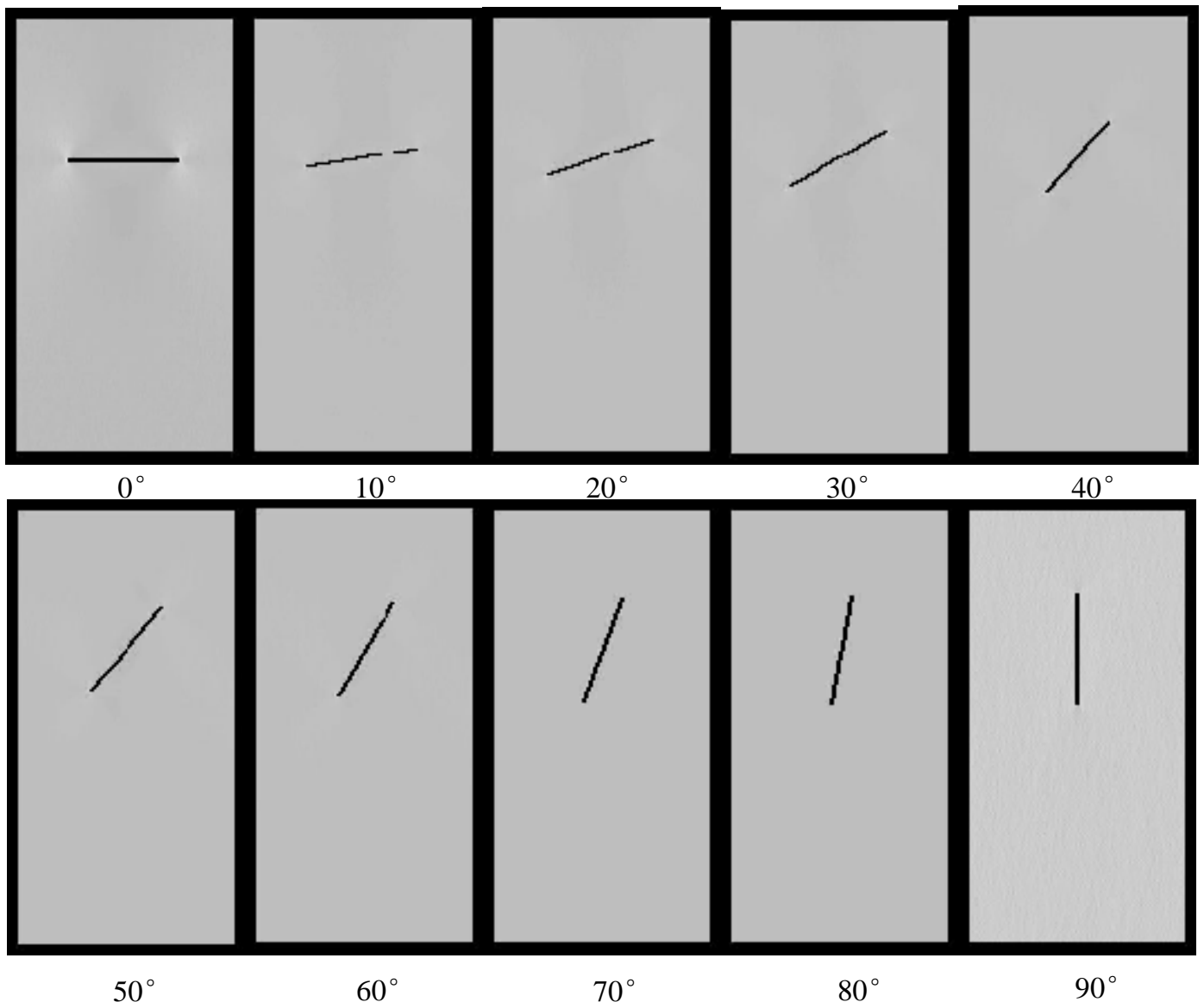

Fig.1 Numerical Models of Jointed Rock Masses with Different Inclined Angles

\section{Results Analysis of Numerical Tests}

For the rock mass models without joint, the main cracks of macroscopic damage connected between left and right sides of model, but the location of main cracks is uncertainty because of the heterogeneity of rock material, and the main crack angle is not entirely consistent and random (Fig. 1). The macroscopic failure modes almost are same except the joint inclined angle is $90^{\circ}$ (Fig.2), but the peak strength are different, the overall trend is the peak strength became bigger as the inclined angle raising, in specially the amplification of peak strength increased when the inclined angle beyond $60^{\circ}$. The peak strength which the inclined angle is $90^{\circ}$ was close to the rock mass without joint (Fig.3). 

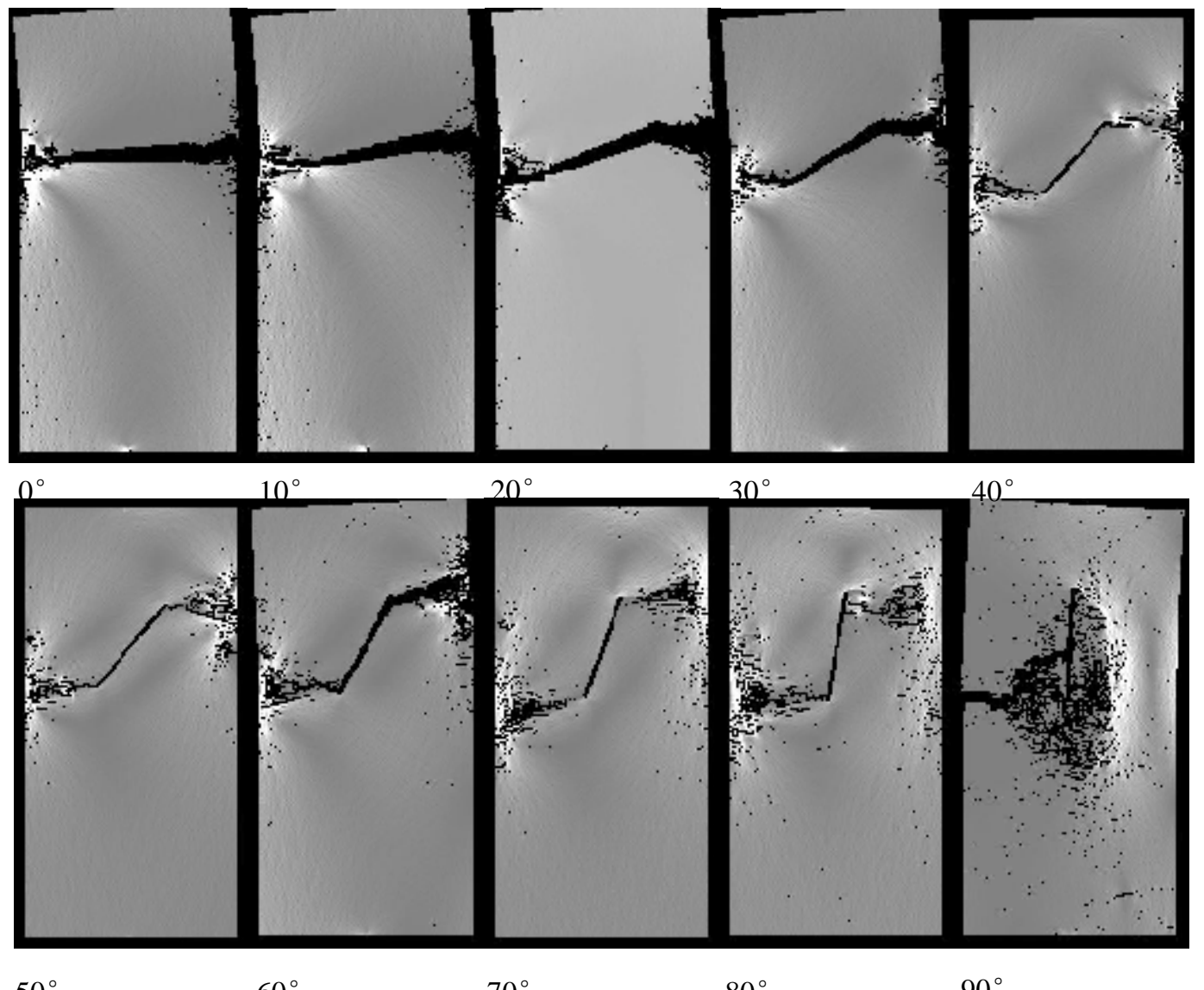

$50^{\circ}$

$60^{\circ}$

$70^{\circ}$

$80^{\circ}$

$90^{\circ}$

Fig.2 Macroscopic Failure Results of Jointed Rock Masses with Different Inclined Angles

Above of this, it shows that joints have significant impact for the macroscopic failure mode of rock mass, the direction of the main crack and the peak strength, on the rock sample containing a single trace same long joint under the conditions of directly tensile the joint angle of intensity and so on have significant impact. Associated with rock mass in the mining, hydroelectric power, transportation, civil engineering, both design and construction, should be pay full attention to discontinuity surface, such as joint, according to the different rock mass stress direction and the joint angle, formulating the corresponding solution measures, to ensure the safety of the project and efficient.

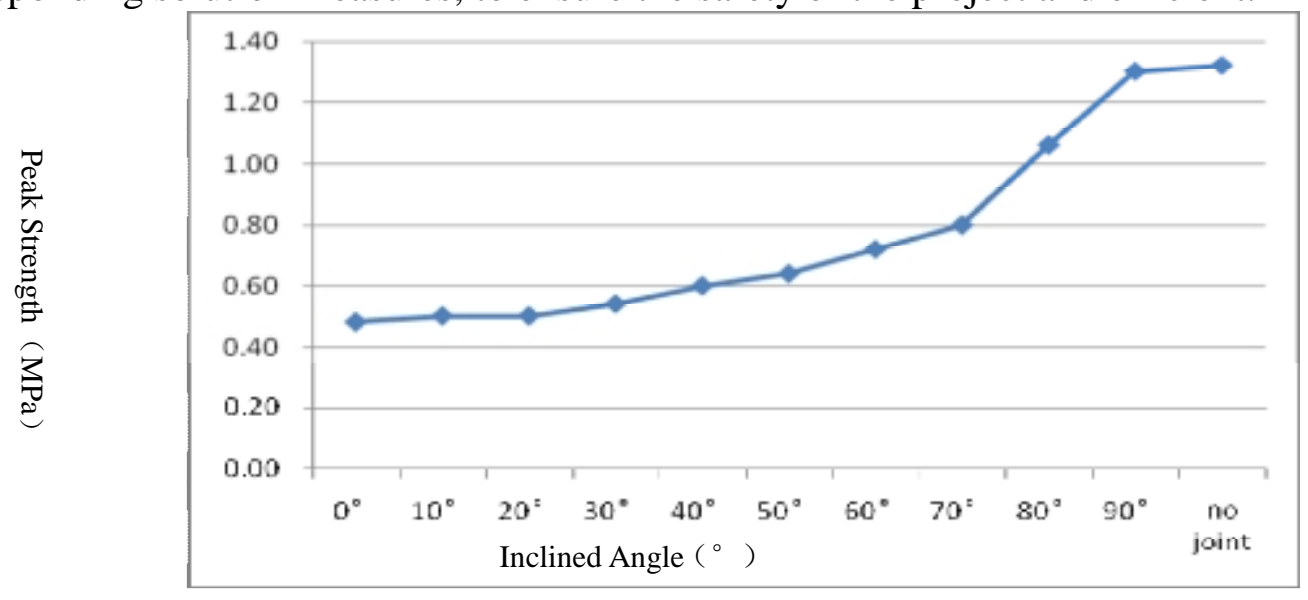

Fig.3 Curve of Joint Inclined Angle and Peak Strength

\section{Conclusion}

This article finished the numerical tests on jointed rock masses with a same length joint which in different joint angle under directly tensile condition, obtained the corresponding failure process, and analysed the macroscopic damage characteristics of the jointed rock mass, the main conclusions are 
following:

1. The direction and location of main crack are randomness on rock masses without joint because of the heterogeneity of rock, and its peak strength is bigger than all of the rock masses with joints.

2. The macroscopic failure modes almost are same on all jointed rock masses with a same length and different angle joint except the joint inclined angle is $90^{\circ}$, the main cracks are connected with the side points of joint from two sides of models.

3. All peak strength of jointed rock masses models are smaller than the rock masses without, joint, the overall trend is the peak strength became bigger as the inclined angle raising, in specially the amplification of peak strength increased when the inclined angle beyond $60^{\circ}$. The peak strength which the inclined angle is $90^{\circ}$ was close to the rock mass without joint.

The angle of joint produce obvious effects to the strength and failure properties of rock masses, so we should pay full attention to joint angle in process of design and construction, according to the different rock mass stress direction and the joint angle, formulating the corresponding solution measures, to ensure the safety of the project and efficient. But the structure of rock mass is complicated and varied, and the stress condition is very complex, this article has carried on the simple containing only a single standard of precast joint rock sample numerical tests of directly tensile, for more complex conditions contain the failure properties of the jointed rock masses in the further research in the future.

\section{Acknowledgements}

This work was financially supported by the Excellent Young Scholars Growth Plans of Liao'ning Educational Committee (LJQ2013033).

\section{References}

[1] Brown E T. Strength of models of rock with intermittent joints[J]. Journa1 of the Soil Mechanics and Foundations Division, 1970,96(6): 1935-1949.

[2] BAI Shi-wei, REN Wei-zhong, FENG Ding-xiang. Research on the strength behavior of rock containing coplanar close intermitent joints by direct shear test $[\mathrm{J}]$. Rock and Soil Mechanics, 1999,20(2): 10-16. (in Chinese)

[3] Bobet A, Einstein H H. Fracture coalescence in rock-type materia1 under uniaxial and biaxial compressions[J]. International Journal of Rock Mechanics and Mining Sciences, 1998,35(7):863-888.

[4] Chen Hong-kai, Tang Hong-mei. Method for calculating strength parameters of structura1 planes controlling the rock block stability[J]. Journal of Engineering Geology,2008,16(1):37-41. (in Chinese)

[5] Tiwari R P, Seshagirik. Post failure behaviour of a rock mass under the influence of triaxial and true triaxial confinement[J]. Engineering Geology,2006,84(3/4): 112-129.

[6] Barton N, Bandis S, Bakhtar K. Strength, deformation and conductivity coupling of rock joints[J]. International Journal of Rock Mechanics and Mining Sciences and Geomechanics Abstracts,1985,22(3):121-140.

[7] Chen Xin, Liao Zhi-hong, Li De-jian. Experimental Study of Effects of Joint Inclination Angle and Connectivity Rate on Strength and Deformation Properties of Rock Masses Under Uniaxial Compression [J]. Chinese Journal of Rock Mechanics and Engineering, 2011,30(4):781-789. (in Chinese)

[8] Tang Chun-an, Fu Yu-fang, Wang Shu-hong. Numerical Tests of Failure Process on Rock[M]. Science Press, 2003. 